\title{
The neuropsychological profile of Othello syndrome in Parkinson's disease
}

\author{
Jennifer A. Foley ${ }^{1,2}$, Thomas T. Warner ${ }^{3} \&$ Lisa Cipolotti $^{1,4}$ \\ ${ }^{1}$ National Hospital for Neurology and Neurosurgery, Queen Square, London, UK \\ ${ }^{2}$ UCL Institute of Neurology, Queen Square, London, UK \\ ${ }^{3}$ Reta Lila Weston Institute of Neurological Studies, UCL Institute of Neurology, London, Queen \\ Square, UK \\ ${ }^{4}$ Dipartimento di Scienze Psicologiche, Pedagogiche e della Formazione, Università degli Studi di \\ Palermo, Palermo, Italy.
}

Corresponding author:

Jennifer A. Foley

Department of Neuropsychology

Box 37

National Hospital for Neurology and Neurosurgery

Queen Square

London, UK

WC1N 3BG. 
Delusions in Parkinson's disease (PD) are rare, but when present are frequently characterised by morbid jealousy, or 'Othello syndrome' (e.g. delusions: 1 in 98 PD patients, Holroyd, Currie \& Wooten, 2001; Othello syndrome: 6 in 16 delusional PD patients, Marsh et al., 2004). The onset of Othello syndrome in PD is often associated with dopamine therapy, particularly dopamine agonists, such as ropinirole and rotigotine (e.g. Poletti et al., 2012). The neuropsychological profile of Othello syndrome in PD remains unknown. We conducted neuropsychological assessment with approximately 400 PD patients and identified five patients with Othello syndrome.

All five patients developed Othello syndrome following the introduction of dopamine agonist therapy. All presented with impulse control disorder of hypersexuality, pathological gambling and/or overshopping. All had early experiences of infidelity and jealousy; all had been betrayed in their first romantic relationships, three of them had been unfaithful (patients 1, 3 and 4) and three reported parental infidelity (patients 3, 4 and 5). All patients described their current partners as being cold and distant to them. All but one had normal brain MRI; patient 1 was found to have mild left frontotemporal atrophy and a few white matter intensities.

Patient 1 was a male, married with children, diagnosed with PD at age 51 years. Following a month of ropinirole treatment, he developed a grave Othello syndrome, hypersexuality and visual hallucinations. The patient became convinced that his wife was having sex with other men, including their son. He was suspicious of her and believed that she had hired a private detective and installed microphones at home. He drilled holes in walls and took up floorboards searching for these. When the ropinirole was reduced, the symptoms abated.

Patient 2 was a female, living with her partner, diagnosed with PD at age 47 years. Following commencement on ropinirole, she developed Othello syndrome, over-shopping and visual illusions. The patient believed that her partner was unfaithful and having affairs with multiple people, including her best friends. Their relationship broke down and they separated, but she falsely believed her partner to be stalking her, trying to get in to her house and tampering with the locks. When ropinirole was stopped, the symptoms disappeared.

Patient 3 was a male, married with one child, diagnosed with PD at age 36 years. Following ropinirole treatment, he developed Othello syndrome, and hypersexuality, over-shopping and gambling. He became very suspicious and jealous of his wife, believing her to be having affairs with several partners. He surreptiously placed recording devices on her and monitored her phone use. Ropinirole was reduced and the Othello symptoms subsided. 
Patient 4 was a female, married, diagnosed with PD at age 50 years. Five years after commencing ropinirole, she developed Othello syndrome, over-spending and visual illusions. She reported intense feelings of jealousy and frequent 'jealousy attacks'. She accused her husband of being unfaithful, believing him to flirt with and ogle other women. She also became concerned that her own family members were trying to steal him away from her. She watched her husband closely and constantly monitored his behaviour.

Patient 5 was a male, married, diagnosed with PD at age 60 years. Three years after commencing rotigotine, he developed Othello syndrome, hypersexuality and visual hallucinations. He described feeling less secure in his relationship and suspicious of his wife, convinced that men were coming into his house. He described visions of his wife flirting with other men, including her undressed with another man in their bedroom.

All Othello patients underwent detailed neuropsychological investigation, evaluating general intellectual functioning, non-verbal and verbal memory, language, visuoperception, processing speed and executive functions (see Table 1). The patients performed in the normal range on tests of general intellectual functioning, verbal memory, language and processing speed. Patients 1, 2 and 3 had impaired non-verbal memory and patient 5 impaired visuoperception. Strikingly, all Othello patients were impaired on two executive tests traditionally thought to assess response suppression and recently shown to involve lateralised right and left prefrontal circuits respectively (Cipolotti et al., 2016). Thus, patients 2, 3, 4 and 5 were impaired on the Hayling and patient 1 was impaired on the Stroop.

We compared the cognitive profiles of our Othello patients with those of five patients with PD without Othello syndrome. These patients were selected from a larger PD patient database to be matched to our Othello patients for age, age at disease onset, NART, education (all $t$-tests $p>.05$ ) and drug treatment. All non-Othello patients were on dopamine agonists, with one presenting with impulse control disorder of hypersexuality (non-Othello patient 1 ). The non-Othello patients had a longer mean disease duration (mean: 14.40 years, SD: 2.61 versus mean: 5.80 years, SD: $3.27, t(8)=$ 4.60, $p<.005$ ). The non-Othello patients demonstrated scattered cognitive impairments, without a clear pattern of performance (see Table 1). Notably, none of them demonstrated impairment on either the Hayling or Stroop tests.

Performance on the Hayling and Stroop require not only response suppression, but also a variety of other complex processes. For example, on the Hayling, strategy implementation is also needed to generate semantically-unrelated alternative sentences. We investigated further if our Othello patients' impairment on the Hayling could be ascribed to a deficit in response suppression or strategy implementation. We administered a revised version of the Hayling, thought to be able to distinguish 
between these two possibilities, to patients 3, 4 and 5 (Robinson et al., 2016). We found that the Othello patients performed flawlessly when provided with a strategy.

As previously reported, our Othello patients developed their delusional jealousy on the background of dopamine agonists. These drugs are known to have significant behavioural sequelae, including impulse control disorder and delusional syndromes (see Connolly \& Lang, 2014 for a review). Indeed, all our Othello patients also had impulse control disorder and paranoid ideation. It has been suggested that these behavioural sequelae reflect the uneven pattern of dopaminergic loss in the striatum and the relative 'overdosing' of intact ventral structures, including the nucleus accumbens (Cools et al., 2003). The ventral striatum is known to be involved in reward and reinforcement learning, particularly of natural rewards such as sex and bonding (Ortigue, 2010). Excessive dopaminergic stimulation may allow loving relationships to become infused with an aberrant level of salience, demanding greater attention; thereby providing the biological substrate for the development of the delusional jealousy. However, our non-Othello patients were also on dopamine agonists at time of testing, yet showed no morbid jealousy. This suggests that dopamine therapy may be a necessary, but not sufficient factor in the development of the Othello syndrome.

Reports from non-neurological populations have documented that Othello syndrome is associated with previous experience of infidelity and/or sexual jealousy (Cipriani et al., 2012). Othello syndrome is also commonly reported following a sudden disparity between the patient's and partner's desire for sex, in both neurological and non-neurological populations (e.g. Todd \& Dewhurst, 1956). Notably all our Othello patients suffered earlier in life from infidelities and jealousy, and reported a feeling of emotional rejection within their current relationships. Patients 1,3 and 5 also admitted to hypersexuality and experienced sexual rejection. We would like to suggest previous experience of infidelity, combined with feelings of rejection, and an aberrant level of relationship salience may have triggered delusional jealousy.

Moreover, the reported neuropsychological impairment in response suppression may be responsible for maintaining the delusional jealousy, despite clear disconfirmatory evidence. In three of our Othello patients, we also documented impaired strategy implementation. This may prevent disengagement from a prepotent or habitual response, allowing our patients' delusional jealousy to persist. Interestingly, strategy implementation impairments have been previously documented following lesions to the right prefrontal cortex (Cipolotti et al., 2016; Robinson et al, 2015). Othello syndrome has also been described following right frontal focal lesions (e.g. Graff-Radford et al., 2012). The right ventromedial prefrontal cortex is known to be involved in processing jealousy (Shamay-Tsoory, Tibi-Elhanany \& Aharon-Peretz, 2007). Our patients' known basal ganglia 
pathology is likely to have disrupted the connections with the right prefontal cortex (e.g. Cools et al., 2002), and we suggest that this may underlie their delusional jealousy. 


\section{References}

Cipolotti, L., Spanò, B., Healy, C., Tudor-Sfetea, C., Chan, E., White, M., Biondo, F., Duncan, J., Shallice, T. \& Bozali, M. (2016). Inhibition processes are dissociable and lateralised in human prefrontal cortex. Neuropsychologia, 9, 1 - 12.

Cipriani, G., Vedovello, M., Nuti, A. \& di Fiorino, A. (2012). Dangerous passion: Othello syndrome and dementia. Psychiatry and Clinical Neurosciences, 66, $467-473$.

Connolly, B.S. \& Lang, A.E. (2014). Pharmacological treatment of Parkinson disease: A review. JAMA, 311, $1670-1683$.

Cools, R., Barker, R.A., Sahakian, B.J. \& Robbins, T.W. (2003). L-Dopa medication remediates cognitive inflexibility, but increases impulsivity in patients with Parkinson's disease. Neuropsychologia, 41, $1431-1441$.

Cools, R., Stefanova, E., Barker, R.A., Robbins, T.W. \& Owen, A.M. (2002). Dopaminergic modulation of high-level cognition in Parkinson's disease: the role of the prefrontal cortex revealed by PET. Brain, 125, 584 - 594.

Graff-Radford, J., Whitwell, J.L., Geda, Y.E. \& Josephs, K.A. (2012). Clinical and imaging features of Othello's syndrome. European Journal of Neurology, 19, 38 - 46.

Holroyd, S., Currie, L. \& Wooten, G.F. (2001). Prospective study of hallucinations and delusions in Parkinson's disease. Journal of Neurology, Neurosurgery \& Psychiatry, 70, 734 - 738.

Marsh, L., Williams, J.R., Rocco, M., Grill, S., Munro, C. \& Dawson, T.M. (2004). Psychiatric comorbidities in patients with Parkinson disease and psychosis. Neurology, 63, $293-300$.

Ortigue, S., Bianchi-Demicheli, F., Patel, N., Frum, C \& Lewis, J.L. (2010). Neuroimaging of love: fMRI meta-analysis evidence toward new perspectives in sexual medicine. Journal of Sexual Medicine, 7, 3541 - 3552 .

Poletti, M., Perugi, G., Logi, C., Rolmano, A., Del Dotto, P., Ceravolo, R., Rossi, G., Pepe, P., Dell'Osso, L. \& Bonuccelli, U. (21012). Dopamine agonists and delusional jealousy in Parkinson's disease: A cross-sectional prevalence study. Movement Disorders, 27, 1679 - 1682. 
Robinson, G.A., Cipolotti, L., Walker, D.G., Biggs, V., Bozzali, M. \& Shallice, T. (2015). Verbal suppression and strategy use: A role for the right lateral prefrontal cortex. Brain, 138, $1084-1096$.

Robinson, G.A., Walker, D.G., Biggs, V. \& Shallice, T. (2016). When does a strategy intervention overcome a failure of inhibition? Evidence from two left frontal brain tumour cases. Cortex, 79, $123-$ 129.

Todd, T. \& Dewhurst, K. (1956). The Othello syndrome: A study in the psychopathology of sexual jealousy. Journal of Nervous and Mental Disease, 122, 367 - 374. 


\section{Supplementary Material}

Neuropsychological Test References

Burgess, P. W., \& Shallice, T. (1997). The Hayling and Brixton Tests. Bury St Edmunds, UK: Thames Valley Test Company.

McKenna, P., \& Warrington, E. K. (1983). The Graded Naming Test. Windsor, UK: NFER Nelson.

Nelson, H.E. (1976). A modified card sorting test sensitive to frontal lobe defects. Cortex, 12, 313 324.

Nelson, H.E. (1982). National Adult Reading Test. Windsor, UK: NFER - Nelson.

Reitan, R.M. \& Wolfson, D. (1985). The Halstead-Reitan Neuropsychological Test Battery: Therapy and clinical interpretation. Tucson, AZ: Neuropsychological Press.

Smith, A. (1982). Symbol Digits Modalities Test. Los Angeles: Western Psychological Service.

Trenerry, M. R., Crosson, B., DeBoe, J., \& Lebere, W. R. (1989). Stroop Neuropsychological Screening Test. Odessa, Florida: Psychological Assessment Resources.

Warrington, E. K. (1984). Recognition Memory Test: RMT. Windsor, UK: NFER - Nelson.

Warrington, E. K. \& James, M. (1991). The Visual Object and Space Perception Battery. Bury St Edmunds, UK: Thames Valley Test Company.

Wechsler, D. (1997). WAIS-III. San Antonio, Texas: Psychological Corporation. 
Table 1: Neuropsychological performance of the four PD patients with Othello syndrome and four PD patients with no history of Othello syndrome (with impaired performance highlighted in bold).

\begin{tabular}{|c|c|c|c|c|c|c|c|c|c|c|}
\hline & \multicolumn{5}{|c|}{$P D+$ Othello } & \multicolumn{5}{|c|}{$P D-$ Othello } \\
\hline & Case & Case & Case & Case & Case & $P D 1$ & $P D 2$ & $P D 3$ & $P D 4$ & PD5 \\
\hline & 1 & & 3 & 4 & & & & & & \\
\hline \multicolumn{11}{|l|}{ Intellectual functions } \\
\hline NART PFSIQ & 122 & 91 & 92 & 126 & 126 & 121 & 87 & 95 & 114 & 124 \\
\hline WAIS-III FSIQ & 89 & 90 & 84 & 114 & 83 & 104 & 100 & 102 & 105 & 118 \\
\hline \multicolumn{11}{|l|}{ Memory } \\
\hline RMT - Words & $38 / 50$ & $50 / 50$ & $50 / 50$ & $50 / 50$ & $36 / 50$ & $48 / 50$ & $37 / 50$ & $49 / 50$ & $47 / 50$ & $48 / 50$ \\
\hline RMT - Faces & $34 / 50$ & 34/50 & $36 / 50$ & $47 / 50$ & $38 / 50$ & $38 / 50$ & $44 / 50$ & $40 / 50$ & $46 / 50$ & $44 / 50$ \\
\hline \multicolumn{11}{|l|}{ Language } \\
\hline Graded Naming Test & $25 / 30$ & $18 / 30$ & $16 / 30$ & $27 / 30$ & $24 / 30$ & $28 / 30$ & $22 / 30$ & $22 / 30$ & $27 / 30$ & $28 / 30$ \\
\hline \multicolumn{11}{|l|}{ Visuoperception } \\
\hline Incomplete & - & - & $20 / 20$ & - & $10 / 20$ & - & - & - & - & - \\
\hline \multicolumn{11}{|l|}{ Letters } \\
\hline VOSP Silhouettes & $17 / 30$ & $20 / 30$ & - & $22 / 30$ & - & $26 / 30$ & $24 / 30$ & $23 / 30$ & $24 / 30$ & $19 / 30$ \\
\hline \multicolumn{11}{|l|}{ Executive function } \\
\hline Stroop completed & 40 & 112 & 94 & 78 & - & 76 & 102 & 93 & 72 & 89 \\
\hline $\begin{array}{l}\text { Hayling B errors (scaled } \\
\text { score) }\end{array}$ & - & 2 & 2 & 3 & 3 & 7 & 5 & 7 & 6 & 8 \\
\hline Verbal fluency - 'S' & 8 & 17 & 25 & 18 & 15 & 29 & 10 & - & 13 & 21 \\
\hline MCST categories & - & $6 / 6$ & $6 / 6$ & - & - & $6 / 6$ & $4 / 6$ & $6 / 6$ & $4 / 6$ & $6 / 6$ \\
\hline \multicolumn{11}{|l|}{ Processing speed } \\
\hline TMT-A time (seconds) & 48 & 45 & - & 54 & - & 56 & 47 & 31 & 54 & 59 \\
\hline SDMT & 31 & - & - & - & - & - & - & - & - & - \\
\hline WAIS-III PSI & - & 93 & - & 86 & - & 103 & - & 108 & 93 & 91 \\
\hline
\end{tabular}

NART PFSIQ: National Adult Reading Test, Predicted Full Scale IQ (Nelson, 1982); WAIS-III: Wechsler Adult Intelligence Scale Third Edition (Wechsler, 1997); RMT: Recognition Memory Test (Warrington, 1984); Graded Naming Test (McKenna \& Warrington, 1983); VOSP: Visual Object and Space Perception Battery (Warrington \& James, 1991); Hayling: Hayling Sentence Completion Test (Burgess \& Shallice, 1997); Stroop (Trenerry et al., 1989); MCST: Modified Card Sorting Test (Nelson, 1976); Brixton: Brixton Spatial Anticipation Test (Burgess \& Shallice, 1997); TMT: Trail Making Test (Reitan \& Wolfson, 1985); SDMT: Symbol Digit Modalities Test (Smith, 1982); PSI: Processing Speed Index.; - : not tested. 